\title{
Compartilhamento de práticas formativas em matemática escolar por professoras alfabetizadoras
}

\author{
Regina Célia Grando \\ Adair Mendes Nacarato ${ }^{2}$ \\ A aprendizagem do adulto se dá primordialmente, no grupo, no \\ confronto e no aprofundamento de idéias, pela escolha \\ individual e comprometida com o evento a ser conhecido. Esse \\ evento, que se apresenta em sua multiplicidade, se ancora na \\ experiência do aprendiz, significada pela linguagem
}

(Placco \& Souza, 2006, p. 24)

\begin{abstract}
Resumo: O texto analisa práticas formativas num grupo de professoras alfabetizadoras, que fazem parte do projeto Observatório da Educação, intitulado "Estudos e pesquisas de práticas de letramento matemático escolar e de formação docente”, da Universidade São Francisco, Itatiba, SP, relativo ao período 2013-2014. O projeto tem por objetivo investigar, por meio de um trabalho colaborativo com professoras da educação básica, as práticas de letramentos matemáticos escolares, bem como as práticas de formação docente de professoras que ensinam matemática. Entende-se que as práticas das professoras, quando sistematizadas em forma de narrativa e compartilhadas no grupo de pesquisadores e em eventos científicos, possibilitam um letramento acadêmico de todos os envolvidos. Dessa forma, tomam-se como objeto de análise os momentos de compartilhamento das narrativas das professoras no grupo de pesquisadoras e em eventos científicos, entendendo-as como experiências formativas.
\end{abstract}

Palavras-chave: letramento matemático escolar, formação de professores, anos iniciais, letramento do professor

\section{The sharing of formative practices in school mathematics by literacy teachers}

\begin{abstract}
The text analyses formative practices in a group of literacy teachers, who are part of the Observatory of Education project, called "Studies and researches of school mathematics literacy practices and of teaching training", of the São Francisco University, Itatiba, SP, for the period of 2013-2014. The project aims to investigate, through a collaborative work with basic education teachers, the school mathematical literacies practices, as well as the teachers' formation practices of teachers who teach mathematics. We understand that the teachers' practices when are systematized in a narrative form and shared in the researchers group and in scientific events make an academic literacy of all of the involved possible. In this way, we take as object of

1 Doutora em Educação pela Unicamp em 200o. Professora do Departamento de Metodologia de Ensino da Universidade Federal de São Carlos. E-mail: regrando@yahoo.com.br.

2 Doutora em Educação pela Unicamp em 200o. Professora do Programa de Pós-graduação Stricto Sensu em Educação da Universidade São Francisco. E-mail: adamn@terra.com.br.
\end{abstract}


analysis the sharing moments of the teachers' narratives in the researchers group and in scientific events, understating them as formative experience.

Keywords: school mathematics literacy, teachers training, early years, teacher literacy

\section{Introdução}

A pesquisa apresentada neste texto está sendo desenvolvida no âmbito do projeto Observatório da Educação (OBEDUC), intitulado "Estudos e pesquisas de práticas de letramento matemático escolar e de formação docente”, que tem por objetivo investigar, por meio de um trabalho colaborativo com professoras da educação básica, as práticas de letramentos escolares, mais especificamente, o letramento matemático, bem como as práticas de formação docente de professoras que ensinam matemática. O projeto está centrado no letramento matemático das crianças no ciclo de alfabetização (1o ao 3o ano do Ensino Fundamental), por meio da parceria entre professoras da escola pública que ensinam matemática nos anos iniciais do ensino fundamental, pós-graduandas e professoras da universidade. A pesquisa contempla três eixos que se articulam, a saber: 1) parceria universidade-escola: possibilidades de "dar voz e ouvidos" aos professores escolares e da universidade, a fim de subsidiar políticas públicas; 2 ) transformações nas concepções e nas práticas dos professores, decorrentes do trabalho de parceria desenvolvido;3) análise da circulação de ideias matemáticas dos alunos por meio da investigação dos processos de oralidade, leitura e escrita. Acreditamos que, quando as professoras são produtoras de conhecimento em práticas de letramento, os três eixos são contemplados.

Uma das atribuições do professor da Educação Básica participante/pesquisador do projeto é "elaborar uma proposta inovadora de ensino/aprendizagem na área ou disciplina em que atua ou em aspectos da vida escolar e, preferencialmente, na escola em que está lotado" (Coordenação de Aperfeiçoamento de Pessoal de Nível Superior - Capes, 2012, p. 17). Dessa forma, as professoras da escola assumem o papel de protagonistas de práticas de letramento matemático escolar em suas salas de aula, uma vez que realizam estudos teóricos no grupo de pesquisadores, elaboram e desenvolvem práticas de letramento inovadoras com os alunos. Em seguida, escrevem e compartilham suas narrativas oralmente no grupo de pesquisadores. Ali as narrativas são tomadas como objeto de análise e estudo. Há o confronto entre a teoria e as práticas escolares; há o compartilhamento de ideias; há apropriações da prática da outra professora e a ousadia de também experimentá-la em suas salas de aula; e há a reescrita de narrativas para a divulgação/publicação. Dessa forma, vai se construindo colaborativamente um conjunto de práticas de letramento matemático escolar para o ciclo de alfabetização por meio das narrativas dessas professoras. Todo esse movimento é registrado em audiogravações e documentado - documentação narrativa, contendo as narrativas produzidas pelas professoras. 
Neste texto, tomamos como objeto de análise o compartilhamento das narrativas das professoras, entendendo tais narrativas como experiências formativas. Acreditamos que as práticas das professoras, quando são escritas e narradas no grupo de pesquisadores do OBEDUC e em eventos científicos, possibilitam um letramento acadêmico a elas e às pesquisadoras.

\section{Compartilhamento de práticas como experiência formativa}

A possibilidade de constituição de comunidades de investigação entre professores da Educação Básica, professores da universidade e pós-graduandos, que muitas vezes também são professores escolares, tem se mostrado potencializadora de desenvolvimento profissional docente (Cochran-Smith \& Lytle, 1999; Jaworsky, 2009; Nacarato \& Grando, 2011). O grupo se constitui em um espaço comum, um lugar de produção de conhecimento sobre o ensino, a aprendizagem, os conteúdos escolares, os cotidianos escolares, as práticas e as teorias de professores escolares e da universidade. Quando adjetivamos os professores, não o fazemos no sentido de estabelecer uma diferenciação ou hierarquização, mesmo porque nossa concepção de comunidades de investigação é de que todos os participantes assumem o mesmo status no grupo e contribuem com seus saberes e conhecimentos sobre a temática investigada. Trata-se de uma forma de identificar os participantes em seu lugar de atuação, considerando as especificidades de seus objetivos e interesses.

Em tais comunidades, mesmo que com objetivos diferentes, é possível a troca, a experiência em prol da aprendizagem e da melhoria do ensino na Educação Básica. Para o professor da escola, muitas vezes, a participação se dá por uma necessidade de continuar sua formação, repensar práticas e teorias, ter um espaço para compartilhar suas ideias e propostas, as angústias e os desafios enfrentados em seu cotidiano escolar, bem como de apropriar-se de um conhecimento acadêmico que, com frequência, fica restrito à universidade, como: leitura de pesquisas, dissertações e teses; e apropriações de metodologias de pesquisa e de modos de produção acadêmica. Para o professor da universidade, há o interesse de acompanhar: a maneira como os professores se desenvolvem profissionalmente, participando de grupos de natureza colaborativa; os modos de produção de conhecimento pelos alunos; e a forma como a escola se constitui em um espaço de entrecruzamento de culturas (cultura escolar, da escola, dos professores, de aula, de gestão, de infância, de juventude, de referência dos alunos, etc.).

Nessas comunidades os professores se desenvolvem profissionalmente em um processo contínuo e inconcluso, que envolve o crescimento pessoal e a formação profissional (inicial e continuada). "A formação contínua, portanto, é um fenômeno 
que ocorre ao longo de toda a vida e que acontece de modo integrado às práticas sociais e às cotidianas escolares de cada um, ganhando intensidade e relevância em algumas delas." (Passos et al., 2006, p. 195).

No interior das comunidades de investigação é possível que o professor se transforme, transforme suas práticas escolares e também as institucionalizadas, por meio da reflexão, do estranhamento, do questionamento e do compartilhamento de práticas e ações no seu ambiente de trabalho. Quando no grupo há respeito mútuo, confiança compartilhada e ética nas relações estabelecidas, o professor se sente à vontade, se sente empoderado e ousa apresentar suas práticas, refletir, analisar e, até mesmo, questionar teorias.

Dessa forma, as práticas compartilhadas dos professores são tomadas como objetos de investigação no grupo, e seus participantes refletem, discutem, analisam os modos de pensar dos alunos, as formas como as ações aconteceram em aula, a forma como o texto é escrito, etc. A reescrita de tais práticas, muitas vezes, possibilita novas aprendizagens, transformações. É nesse sentido que podemos dizer que tais transformações se constituem em uma experiência autêntica, no sentido defendido por Larrosa (2004):

A experiência é sempre de alguém, subjetiva, é sempre aqui e agora, contextual, finita, provisória, sensível, mortal, de carne e osso, como a vida mesma. A experiência tem algo da opacidade, da obscuridade e da confusão da vida, algo da desordem e da indecisão da vida. Por isso, na ciência tampouco há lugar para a experiência, por isso a ciência também menospreza a experiência, por isso a linguagem da ciência tampouco pode ser a linguagem da experiência. (p. 22)

Quando a experiência de um participante da comunidade é compartilhada, o outro se apropria do que foi dito, em uma experiência de ouvir, questionar, argumentar, buscando atribuir sentidos e significados ao que foi vivenciado, ao que foi experienciado pelo seu parceiro de comunidade. Mas, como a experiência do que foi vivido não é a dele, ele a ressignifica para uma outra experiência na sua sala de aula, no seu contexto de atuação. Dessa forma, a experiência assume seu papel formativo para o participante que compartilha sua experiência e para o parceiro que ousa experimentá-la, também, em sua sala de aula. Uma experiência formadora em que, segundo Ribetto (2011), apropriando-se das ideias de Larrosa (2002), é possível reconhecer a "formação que não se sabe":

Essa formação na e desde a experiência só é possível de ser padecida - no sentido da paixão mesmo - se suspendemos ou interrompemos nossa tranqüilidade formativa. Quer dizer, se abandonamos as certezas de uma formação prescritiva, tecnocrática, asséptica e, o que, fundamen- 
talmente, se sabe antes de que aconteça... pois, porque se sabe, impossibilita que aconteça alguma coisa que não tenha sido planejada. Para pensar uma formação na e desde a experiência é necessário possibilitar padecer o não saber inerente ao acontecimento. (p. 114)

A autora faz referência a textos de Larrosa que, de certa forma, discutem essa importância da experiência formativa como aquela que não pode ser predeterminada, antecipada, mas que simplesmente acontece, traz uma ruptura com o que foi anteriormente experimentado, vivido, e possibilita o espaço para a inovação, para a novidade. (Ribetto, 2011) aponta:

Em dois textos belíssimos, Jorge Larrosa traz as metáforas do aprender a ler sem saber ler, ou de aprender de ouvidos... (LARROSA, 2004) que me ajudam a pensar - por deslocamento de conceitos - na formação que não se sabe antes do encontro... a formação como alteridade, como aquilo no qual entramos sem saber o que vamos encontrar, apreender, ler, escrever... ou, ainda, se vamos encontrar alguma coisa. Nessa formação, o mais importante não seriam os conteúdos curriculares, os temas, as unidades de discussão, os textos e as relações que estabelecemos com eles. "E essa relação tem uma condição essencial: que não seja de apropriação, mas de escuta (133) (...) na escuta alguém está disposto a ouvir o que não sabe, o que não quer, o que não precisa. Alguém está disposto a perder o pé e a deixar-se tombar e arrastar por aquilo que procura" (LARROSA, 2002:134). (p. 114)

Dentre as diferentes formas de registro de práticas de professores, temos adotado a narrativa. Consideramos que narrar é produzir história de si, é atribuir sentidos ao vivivido, tal como defende Delory-Momberger (2008):

A narrativa realiza sobre o material indefinido da experiência vivida um trabalho de homogeneização, ordenação e funcionalidade significante: ela reúne, organiza, tematiza os acontecimentos da existência, dá sentido a um vivido multiforme, heterogêneo, polissêmico. É a narrativa que dá uma história a nossa vida: nós não fazemos a narrativa de nossa vida porque temos uma história; temos uma história porque fazemos a narrativa de nossa vida. [destaques no original]. (p. 97)

Entendemos, assim, que no ato da produção da narrativa há sempre um movimento interligando passado (vivido, experienciado, selecionado para ser compartilhado), presente (o momento da reflexão, da escolha do que será dito, da experiência em si) e futuro (como se projetar para novas práticas). A escritura da narrativa é também uma experiência formativa, bem como constitui fontes de história do ensino de matemática. Além disso, para a professora que narra, é a constituição de um fragmento de sua trajetória profissional, de sua história como professora. 
Nesse sentido, entendemos a experiência formativa na comunidade de investigação como aquela que surge de uma construção coletiva de conhecimentos e saberes novos, cuja emersão somente a parceria e as relações humanas entre os participantes possibilitam. As interações ocorridas no interior das comunidades favorecem a produção, pelos participantes, de sentidos - construídos com base nas experiências de cada um - que circulam e atribuem ao conhecimento novos significados.

\section{Letramento acadêmico do professor}

Entendemos o letramento como prática social ${ }^{3}$ e, dessa forma, as atividades de letramento são inúmeras dentro de diversos contextos. Alguns autores preferem falar em multiletramentos e/ou letramentos múltiplos (Kleiman, 1995; Rojo, 2009; Street, 2004), ou somente letramentos, referindo-se às várias adjetivações possíveis (escolar, digital, acadêmico, matemático, em língua, etc.). A escola e a universidade são responsáveis pela apropriação de um letramento específico: o letramento acadêmico. O termo "letramento acadêmico" tem sido utilizado na literatura como uma das formas de análise da apropriação do estudante de graduação dos modos de leitura e escrita acadêmicos. Assim, Lea e Street (citados por Cruz, 2007), discutem as três principais abordagens sobre as quais a escrita do estudante universitário é compreendida: indicam modelo dos estudos das habilidades, modelo da socialização acadêmica e modelo do letramento acadêmico. Nosso objetivo, neste texto, é compreender o letramento acadêmico como prática social, na qual leitura e escrita são socialmente contextualizadas e vão sendo apropriadas no ambiente escolar e universitário. Conforme aponta Cruz (2007):

as práticas escriturais acadêmicas são práticas sociais e, por isso, variam em função do contexto, da cultura e do gênero em que se inserem, pois asseveram que as práticas de letramento nas disciplinas acadêmicas estão associadas aos usos e às funções da escrita em comunidades e contextos específicos .... No desenvolvimento do letramento acadêmico, as questões de escrita e de aprendizagem devem ser consideradas mais do ponto de vista epistemológico e identitário, do que uma questão de aquisição de habilidades ou de socialização acadêmica apenas. (p. 7).

Da mesma forma que os estudantes se apropriam de uma escritura e uma leitura acadêmicas quando em contato com as instituições como escola e universi-

3 Entendemos prática social, na perspectiva de Antônio Miguel (2005): "é um conjunto de atividades ou ações físico-afetivo-intelectuais que se caracterizam por ser: 1. conscientemente orientadas por certas finalidades; 2. espácio-temporalmente configuradas; 3 . realizadas sobre o mundo natural e/ou cultural por comunidades de prática cujos membros estabelecem entre si relações interpessoais institucionalizadas; 4 . produtoras de conhecimentos, saberes, ações, tecnologias, discursos, artefatos, obras de arte etc. ou, em palavra, produtoras de formas simbólicas" (p. 147). 
dade, os professores, quando retornam à vida acadêmica, por meio da participação em grupos de pesquisa, em comunidades de investigação, ou por meio dos cursos de pós-graduação e atividades de extensão, revivem a possibilidade de se apropriar de modos acadêmicos de escrita, leitura, produção de pesquisa e divulgação de resultados. Isso tudo também compõe o letramento do professor, que busca, no ambiente universitário, a possibilidade de apropriação de práticas acadêmicas para a compreensão da sua atuação profissional, de seu conhecimento de mundo, de escola, de teorias, de pesquisas, importantes para o seu desenvolvimento pessoal, acadêmico e para as possíveis transformações na sociedade. O conceito de letramento do professor, ou letramento docente, é apontado por Freire e Macedo (1990, citados por Rosso et al., 2011):

a idéia de letramento docente passa a significar uma condição necessária aos professores (sempre em formação), que se coloca como uma condição de realizar uma leitura de mundo e uma leitura da escola, como uma relação entre texto e contexto fundamental para a transformação da educação. Esta leitura do mundo e da escola pode-se converter em atos políticos, por meio dos quais os professores passarão a se responsabilizar pela mudança nas relações educacionais, no interior das escolas, nas políticas públicas educacionais, como também nas práticas sociais injustas. (pp. 123-124)

Concordamos com essa perspectiva crítica de letramento docente, em que esse profissional, ao refletir sobre sua prática e a de seus alunos, teorizando-as em narrativas e compartilhando em comunidades de investigação, nos espaços de divulgação de pesquisa, sentindo-se protagonista e intelectual crítico, é capaz de transformar-se e transformar pessoas e instituições em seu entorno. Os alunos desses professores se percebem com mais espaço para se manifestar em sala de aula, os gestores percebem uma maior autonomia do professor, e esse se sente forte em suas convicções, uma vez que tem a sustentação de uma comunidade, da pesquisa e da transformação de suas concepções e práticas. Se, por um lado, o professor se sente um agente também de transformação de seu entorno, por outro, é altamente desafiador o compromisso assumido:

O desafio do protagonismo ("dizer a sua palavra") é o desafio de apropriar-se da linguagem - entendida aqui no sentido mais amplo possível, como todos os códigos que permitem trocas entre seres humanos - e dizer / escrever a realidade, pois é para isso que se aprende a lê-la. Aquilo que se chama de "competência docente" é um domínio da linguagem educativa, que pode ser aprendido. [destaques no original] (Rosso et al., 2011, p. 116) 
Acreditamos que a experiência formativa vivenciada pelos professores em comunidades de investigação, que envolve a produção oral e escrita de narrativas de suas práticas e das práticas de letramento de seus alunos, bem como a divulgação das práticas e pesquisas desenvolvidas em espaços acadêmicos, contribui para o letramento do professor em uma perspectiva crítica.

\section{$O$ contexto da pesquisa}

A comunidade de investigação constituída no âmbito do projeto OBEDUC, no período 2013-2014, contou com seis professoras escolares (Daniela, Eliana, Elizangela, Ida, Mariana e Selene), duas professoras da universidade (as autoras deste texto), duas mestrandas (Cláudia e Kátia) e uma doutoranda (Cidinéia).

O grupo se reunia quinzenalmente para estudar, elaborar propostas para a sala de aula, organizar a participação em eventos, compartilhar as narrativas, dentre outras ações. Além dessas reuniões, havia também parcerias estabelecidas entre as mestrandas e as professoras escolares, o que demandava reuniões em subgrupos.

O objetivo do texto é buscar indícios de como a produção e o compartilhamento de práticas se constituem em experiências formadoras e em letramento docente.

Para o recorte aqui apresentado, a análise centrou-se em: registros audiogravados dos encontros e transcritos; excertos das narrativas das professoras; e textos e relatórios por elas produzidos no âmbito do projeto.

Para a análise recorremos às enunciações das professoras - orais ou escritas que sinalizavam para esse processo formativo. Assim, ao lermos o material produzido, fomo-nos apoiando no papel da palavra, como signo ideológico, por excelência, na perspectiva bakhtiniana, ou seja: "A palavra está sempre carregada de um conteúdo ou de um sentido ideológico ou vivencial. É assim que compreendemos as palavras e somente reagimos àquelas que despertam em nós ressonâncias ideológicas ou concernentes à vida”. [destaques no original] (Bakhtin/Volochinov, 1997, p.95). Assim, ao apresentarmos os excertos, buscamos a "compreensão da palavra no seu sentido particular, isto é, a apreensão da orientação que é conferida à palavra por um contexto e uma situação precisos" (p. 94). O contexto aqui referido é o da comunidade de investigação, que tinha como objetivo comum o registro, a sistematização e o compartilhamento das práticas.

\section{Quando as professoras “dão a ler seus textos”: experiências formativas no grupo de pesquisadores e nos eventos científicos}

Instituiu-se no grupo uma cultura de produção e de compartilhamento de narrativas de aula de matemática no ciclo de alfabetização, buscando evidenciar as práticas de letramento matemático escolar presentes nas histórias narradas. 
Em um primeiro momento essas narrativas não mereceram um lugar de destaque no grupo, pois valorizávamos as leituras teóricas e a construção de tarefas a serem desenvolvidas em sala de aula. Entretanto, por solicitação de uma das professoras, começamos a ler, compartilhar e analisar tais narrativas. Dessa forma, cada professora do grupo assumiu o compromisso da escrita de uma narrativa mensal. À medida que as narrativas eram produzidas e apresentadas no grupo, percebemos o quanto eram carregadas de sentidos e de significados sobre as práticas de letramento escolar, mas também de sentimentos, reflexões, apropriações teóricas e sínteses que contribuíam para as outras participantes. Também a escrita da narrativa passou por um processo de apropriação do gênero textual, auxiliada pela oralidade que acontecia na comunidade, nos momentos de socialização. Como aponta a professora Daniela:

Para nós, narrativa de professores era também um gênero muito desconhecido, não tinha ideia o que fosse a estrutura, a organização do texto, de que forma eu ia começar, o que eu ia narrar, que ordem colocar. Então, o domínio do gênero foi importante também. (Daniela, registro audiogravado, 22 de outubro de 2014)

A cada reunião o grupo elegia quais narrativas seriam socializadas no próximo encontro. Elas eram enviadas previamente a todas as participantes do grupo, para leitura e comentários. No dia da socialização, a autora do texto iniciava a sua apresentação, justificando a escolha das aulas ali narradas e complementando o texto escrito. Muitas vezes, a narrativa oral complementava a escrita, trazendo riqueza de detalhes.

A professora Elizangela, do $2^{\circ}$ ano, apresentou no grupo a narrativa intitulada "Construindo a reta numérica" e justifica:

O objetivo dessa narrativa é de descrever o processo vivenciado pelos alunos e por mim no momento em que construímos uma Reta Numérica. A finalidade da produção desse material foi de auxiliar os alunos em suas estratégias para resolver situações-problemas de Matemática, visto que eles ainda não conhecem a técnica do algoritmo, necessitando valer-se do cálculo mental para tal. (Narrativa de Elizangela, 2ํano).

A professora conta que a tarefa tinha sido realizada coletivamente e os alunos eram sempre chamados a participar. Faz parte da prática dessa professora uma aula dialogada e problematizada. Nas várias narrativas apresentadas no grupo, no decorrer do ano, Elizangela trouxe diálogos importantes, de um processo de problematização e investigação em sala de aula, mesmo com alunos de $2 \circ$ ano do ensino fundamental. Assim, ela narra: 
Perguntei se elas já conheciam a Reta Numérica, mas me disseram que não e ficaram curiosos em saber o que era, e como usá-la. Iniciei dizendo que cada aluno receberia um cartão contendo o seu número correspondente ao da chamada e que nossa reta teria exatamente o número de alunos da sala. Nesse momento, Yure diz que no dia alguns colegas haviam faltado; perguntei o que poderíamos fazer, logo ele responde que se o número 3 faltou, o aluno correspondente ao número 4 ficaria com o 3 e com o 4, a turma concordou e achou uma boa saída para a situação. Achei interessante a verificação do aluno quanto aos alunos ausentes e sua sugestão para a resolução da questão. (Narrativa de Elizangela, 2o ano)

A professora considera a proposta do aluno e destaca um momento importante em sua narrativa: a antecipação de Yure de um problema ao construir a reta. Isso mostra o quanto os alunos estavam envolvidos na tarefa e, ao mesmo tempo, o quanto nós, participantes do grupo, também esperávamos a solução proposta por eles.

A escrita de tais narrativas e a socialização no grupo possibilitavam uma releitura coletiva e uma depuração do texto, no sentido de perceber o que necessitava ser acrescentado, o que poderia ter sido analisado de outra maneira e o que havia sido priorizado pela professora. Para ela, o exercício de destacar as suas práticas de letramento lhe possibilitava um letramento acadêmico no exercício de produção de informações sobre: a aula, o registro, as reflexões, a seleção, a análise, a escrita narrativa e a socialização oral. Para as outras participantes do grupo, a socialização das narrativas propiciou momentos de leitura e discussão coletiva. Muitas vezes, o professor se apropria da tarefa do outro, com o objetivo de experimentá-la na sua sala de aula, o que é facilitado e estimulado pela leitura do que aconteceu na sala de aula do colega. A professora Daniela, por exemplo, se apropriou das ideias na narrativa de Elizangela no grupo e também propôs a tarefa a seus alunos:

Depois de ler e refletir sobre a narrativa da professora Elizangela "Construindo a reta numérica”, resolvi trabalhar com meus alunos a reta numérica tendo como objetivo proporcionar aos alunos conhecerem uma estratégia de cálculo para resolução de situações problemas em Matemática. [aspas acrescentadas] (Narrativa de Daniela, 2o ano).

As professoras reconhecem o quanto a participação no grupo e o compartilhamento de narrativas se tornam momentos ricos ao letramento docente.

Dá para fazer de modo diferente na sala de aula. O que tem diferença é fazer parte de um grupo. Quando você faz parte de um grupo, você estuda e troca experiências, essa possibilidade aumenta. Esse grupo trabalha unido, colaborativamente. Cada um faz a sua narrativa, depois 
há o compartilhamento, depois me aproprio do que a colega socializou e ressignifico para a minha sala de aula, faço no contexto da minha sala de aula. (Elizangela, registro audiogravado, 22 de outubro de 2014)

Quando você não está em um grupo assim, como professor você não tem o costume de escrever sobre a sua própria prática. Ao refletir sobre tudo aquilo que você vai escrever, você pensar em como vai guardar toda informação, para não esquecer e poder escrever. Se vai gravar, filmar ou fotografar. Olhando para o movimento da escola não é comum ver os professores olhando para a própria prática. Quando estamos aqui no grupo participando desse movimento vemos o quanto a escrita de narrativas tem função para a nossa prática. (Mariana, registro audiogravado, 22 de outubro de 2014)

No conjunto de narrativas produzidas e analisadas, identificamos algumas práticas de letramento docente. A própria estratégia assumida para a produção das narrativas foi sendo construída pelas professoras. Em um dos encontros, a professora Adair questiona:

Adair: Como é que está sendo? Vocês planejam as atividades para fazer as narrativas, ou depois que a aula acontece vocês falam: "Ah! Esta eu vou fazer a narrativa"?

Daniela: Depois que eu faço a aula...

Adair: Como vocês conseguem guardar tudo isso?

Daniela: Aproveito os momentos de formação da escola e escrevo.

(Registro audiogravado, 21 de maio de 2014)

Quando a atividade desenvolvida se revelava interessante, com diálogos ricos entre os alunos e a professora, as colegas também a desenvolviam em sua turma. Evidentemente, nunca uma aula saía igual à outra, pois a professora sempre dava a sua singularidade à tarefa. No entanto, os resultados obtidos com os alunos foram importantes para que o grupo tivesse elementos para analisar as potencialidades de cada tarefa proposta. Isso se evidenciou, por exemplo, num depoimento da professora Eliana: "Cada uma trabalhou de maneira diferente, atividades diferentes e ao mesmo tempo conteúdos parecidos” (Eliana, registro audiogravado, 22 de outubro de 2014).

Visando enriquecer os textos das narrativas, as professoras foram se apropriando de formas de registro em sala de aula: uso do celular no modo gravador, para captar as vozes dos alunos e inseri-las na narrativa; fotos (com o celular) de registros dos alunos para documentar a narrativa; e fotos de situações de sala de aula para discussão com as próprias crianças.

O texto das narrativas foi sendo depurado, com a identificação de práticas de letramento das crianças. Como, no momento da análise, essa era uma preocupação do grupo, elas próprias passaram a registrar em suas narrativas quais eram as prá- 
ticas que evidenciavam naquela aula. As principais práticas de letramento identificadas foram: o diálogo presente em sala de aula, leitura e interpretação de textos de problemas; a escrita e a reescrita de texto de problemas; a construção e a análise de tabelas e gráficos e plantas baixas; outros registros dos alunos; e a produção de fotos, o uso de recursos didáticos (materiais manipulativos, instrumentos de medida, recursos tecnológicos e jogos) (Lúcio, 2015).

Mas, embora as professoras tivessem satisfação em apresentar suas narrativas no grupo, nem sempre isso foi fácil. Para a professora Mariana, a narrativa "é um gênero dolorido", e ela diz: "Ouvir as gravações, olhar para os registros, fazer uma narrativa da sua aula e ter segurança para narrar aquilo que você teve dificuldade não é fácil" (Mariana, registro audiogravado, 22 de outubro de 2014).

As professoras reconhecem o quanto são importantes, no grupo, a cumplicidade e as relações pessoais, para a socialização dessa escrita, ou, mesmo, para a videogravação de uma aula, como diz Cidinéia:

Como é difícil pegar as gravações e os vídeos das nossas aulas e mostrar para as professoras. Depois de um processo de transformação e envolvimento com o grupo isso foi possível. Aqui no grupo existe uma cumplicidade e com os alunos também (Cidinéia, registro audiogravado, 22 de outubro de 2014).

Nesses encontros também há espaço para discutir questões do cotidiano escolar: os problemas que enfrentam com os alunos de inclusão; as questões relativas à gestão; a desvalorização do professor que busca seu próprio desenvolvimento profissional - tanto pelos planos de carreira quanto pelos pares nas escolas. Ocorrem ainda reflexões contributivas para a formação, como, por exemplo, a análise de um livro didático que possibilitou uma tarefa rica em sala de aula, narrada pela professora.

No nível da pesquisa, os professores da escola básica vêm se aproximando desse campo de atuação, construindo ferramentas que lhes possibilitem pesquisar o cotidiano escolar (sala de aula e reuniões pedagógicas) e o letramento acadêmico, principalmente quando elaboram, discutem, escrevem e reescrevem narrativas de aulas. Tais narrativas vêm permeadas de reflexões sobre a prática, bem como carregadas de sentidos e de teorias que vão sendo apropriadas no grupo. Como escreve a professora Selene em seu relatório:

Escrever as narrativas é outra proposta que me permitiu aprimorar o meu olhar para o letramento matemático presente nas ações que planejo em sala de aula. O movimento de escrever implica em retomar aquilo que havíamos planejado e feito, tomando certa distância, podemos elencar aquilo que não deu certo para melhorar numa outra 
oportunidade além de aprimorarmos o que foi exitoso. Ao compartilhar as narrativas nos encontros pudemos enriquecer o nosso repertório de propostas (foram muitas as contribuições de todos). Colocá-las em prática contribuiu para o desenvolvimento das crianças. Fiz com meus alunos do 1 o ano e da Educação Infantil várias delas e obtive bons resultados em todas: da Professora Elizangela sobre a construção da reta numérica e o quadro de números. A atividade envolvendo o uso do dinheiro e o problema aberto da professora Ida (fiz umas adaptações e adequações), as ideias de introduzir e questionar sobre as situações problemas, contribuições das professoras Daniela e Eliana. (Selene, relatório, 05 de janeiro de 2015)

A possibilidade de os professores se sentirem pertencentes a uma comunidade de investigação contribui para uma discussão mais ampla sobre o ensino da matemática, como declara a professora Elizangela em seu relatório:

pude perceber que uma narrativa é uma maneira (dentre outras) de mostrar o trabalho realizado nas salas de aulas, e que é possível trabalhar com qualidade, engajamento, intencionalidade e objetividade no contexto atual que a escola se encontra. As narrativas expostas por nós professoras deixam claro que a matemática não se resume a números ou algoritmos, mostrou a possibilidade de se trabalhar em matemática por meio de diferentes disciplinas, ou gêneros textuais, ainda, considerou os saberes dos alunos, o que se resume aos multiletramentos. (Elizangela, relatório,05 de janeiro de 2015)

Os momentos de preparação de textos para participação em eventos se mostram potencializadores de aprendizagens docentes, visto que as professoras precisam não apenas registrar e analisar suas práticas, mas também refletir sobre elas.

Há também um rico momento de parceria no grupo, pois as professoras da universidade colaboram com as professoras escolares na produção do texto acadêmico. Em alguns momentos elas se articulam em grupo para apresentação de trabalho em evento. Por exemplo, no Congresso de Leitura do Brasil (COLE), em 2014, as professoras Ida, Daniela e Eliana se prepararam colaborativamente, selecionando uma mesma situação problema para seus alunos (1ㅜㄴ 2 e 3o ano, respectivamente), analisando as diferentes estratégias e evidenciando a importância de dar voz e ouvir as estratégias dos alunos. No texto por elas produzido (Souza, Rossi, \& Marassato, 2014), é possível identificar a segurança com que defendem práticas de letramento:

Ao proporcionar um trabalho com diferentes linguagens, os alunos podem ter a oportunidade de expressar seu modo de pensar, essa cultura nas aulas de matemática pode ser evidenciada quando, por exemplo, o professor promove a leitura da situação problema de forma que ao 
acompanhá-la os alunos sentem-se desafiados a resolvê-lo. O gênero textual matemático precisa ser ensinado, pois envolve a comunicação e a formação de sujeitos agentes do e no mundo, o trabalho de mediação e de intervenção do professor deve mobilizar as capacidades de linguagem, ação, capacidades discursivas e linguísticas do contexto de produção desse gênero matemático. Entendemos que quando o aluno está nesse movimento experimenta práticas de letramentos matemáticos nos apontando que para uma aprendizagem significativa são necessárias atividades significativas e desafiadoras. (pp.887-888)

Para as professoras da escola básica, ter um texto publicado em Anais de Congresso ou até mesmo em revista, como é o caso do Cole, constitui-se em momento de valorização de seu fazer docente. Ao relatar no grupo as experiências de participação nesses eventos, as professoras sempre destacam o quanto o trabalho delas é valorizado nas comunicações orais. Elas falam de salas de aula reais, com todos os problemas que uma escola pública possa ter, mas falam com segurança, fundamentadas teoricamente. Como destacou a professora Daniela numa das reuniões: "Nós conseguimos chegar até aqui, fazer o que fazemos em sala de aula, porque estudamos, temos uma teoria que dá subsídios às nossas práticas" (Daniela, relatório, 05 de janeiro de 2015). Isso evidencia o quanto elas estão articulando teoria e prática.

Quando nós, coordenadoras do projeto, produzimos nossos textos para eventos e publicações em periódicos ou capítulos de livro, nós os socializamos com as professoras, o que faz com se sintam valorizadas, como afirma a professora Ida:

Foi gratificante ver nossos trabalhos sendo apresentados pelas professoras Adair e Regina em grandes eventos, provocando em mim, enquanto professora, uma necessidade de estar em contínuo aprendizado, atenta aos ensinamentos proporcionados e orientados pelas professoras e conseguir integrar o que penso, planejo e faço em sala de aula, estar consciente do meu estilo de trabalho e ter uma postura de consolidação do meu aprendizado. (Ida, relatório de 05 de janeiro de 2015)

Nesse movimento contínuo, nos constituímos professoras e pesquisadoras de práticas docentes e, em especial, de práticas de letramento.

\section{Para finalizar...}

Reconhecemos nos professores a existência da investigação como postura (Cochran-Smith \& Lytle, 1999). A partir do momento em que elas precisaram sistematizar suas práticas em narrativas, passaram a ser mais problematizadoras e atentas às respostas dos alunos. Embora sistematizem apenas algumas práticas, as quais elas selecionam para a produção da narrativa, constata-se o quanto se preocupam 
com o registro de suas aulas. Assim, essa postura de problematizar, de estabelecer diálogos que promovam o desenvolvimento dos alunos e de registrar o movimento de sala de aula, as torna protagonistas e pesquisadoras da própria prática, bem como consumidoras críticas das pesquisas produzidas na universidade.

A produção e o compartilhamento de narrativas têm sido uma experiência formativa para os professores e pesquisadores do grupo, o que nos possibilita inferir que o trabalho com narrativas representa uma prática formativa para professores em formação continuada.

A parceria com a universidade tem possibilitado um movimento de mão dupla: ao mesmo tempo em que as professoras da universidade têm a possibilidade de aproximações mais efetivas com as professoras da escola básica e com essa realidade, as professoras da escola pública têm se apropriado das formas de sistematização de suas práticas, por meio de instrumentos metodológicos da pesquisa. O grupo tem assumido, assim, as características de uma comunidade de investigação (Jaworski, 2009), e a pesquisa e sua sistematização em narrativas têm se constituído em práticas formativas.

\section{Referências}

Bakhtin, M. (Volochinov). (1997). Marxismo e filosofia da linguagem (M. Lahud \& Y. F. Vieira, trad.). São Paulo: Hucitec.

Cochran-Smith, M., \& Lytle, S. L. (1999). Relationships of knowledge and practice: teacher learning in communities. Review of Research in Education, 24, 249-305.

Coordenação de Aperfeiçoamento de Pessoal de Nível Superior - Capes. (2012, 30 de outubro). Portaria no. 152. Regulamento do Programa Observatório da Educação. Diário Oficial da União, 31 de outubro de 2012. Seção 1, p. 43. Brasília, DF: Ministério da Educação, Secretaria da Educação Básica, Capes.

Cruz, M. E. A. da. (2007, julho/novembro). O letramento acadêmico como prática social: novas abordagens. Gestão e Conhecimento, 4(1), 3-13.

Delory-Momberger, C. (2008). Biografia e educação: figuras do indivíduo-projeto. Natal: Ed. UFRN; São Paulo: Paulus.

Jaworski, B. (2009). Building and sustaining inquiry communities in mathematics teaching development. In K. Krainer \& T. Wood (Eds.), Participants in mathematics teacher education: individuals, teams, communities and networks. The international handbook on mathematics teacher education (vol. 3, pp. 309-330). Rotterdam, The Nerthelands: Sense Publisher.

Kleiman, A. B. (1995). O que é letramento? In: A. B. Kleiman (Org.), Os significados do letramento: uma nova perspectiva sobre a prática social da escrita (pp. 15-61). Campinas: Mercado de Letras.

Larrosa, J. (2002). Literatura, experiência e formação. In: M. V. Costa, Caminhosinvestigativos: novos olhares na pesquisa em educação (pp. 133-160). Rio de Janeiro: DP\&A. 
Larrosa, J. (2004). Algumas notas sobre experiência e suas linguagens. In: R. L. L. Barbosa (Org.), Trajetórias e perspectivas da formação de educadores (pp. 19-34). São Paulo: Editora UNESP.

Lúcio, C. C. B. (2015). Práticas de letramento matemático narradas por professoras que atuam nos anos iniciais do ensino fundamental. Dissertação de Mestrado em Educação, Programa de Pós-Graduação Stricto Sensu em Educação, Universidade São Francisco, Itatiba, SP.

Miguel, A. (2005, janeiro/abril). História, filosofia e sociologia da educação matemática na formação do professor: um programa de pesquisa. Educação e Pesquisa, 31(1), 137-152.

Nacarato, A. M., \& Grando, R. C. (2011). Formative processes: sharing learning experience in geometry. In: N. Berdnaz, D. Fiorentini, \& R. Huang (Eds.), International approaches to professional development for mathematics teachers (pp. 128-136). Ottawa, Canada: University of Ottawa Press.

Passos, C. L. B., Nacarato A. M., Fiorentini, D., Miskulin, R. G. S., Grando, R. C., Gama, R. P., ..., Melo, M. (2006). Desenvolvimento profissional do professor que ensina matemática: uma meta-análise de estudos brasileiros. Quadrante, 15 (1-2), 193-219.

Placco, V. M. N. S., \& Souza, V. L. (Orgs.). (2006). Aprendizagem do adulto professor. São Paulo: Loyola.

Ribetto, A. (2011, julho/dezembro). Pensar a formação de professores desde a experiência e desde o menor da formação. Reflexão e Ação, 19(2), 109-119.

Rojo, R. (2009). Letramentos múltiplos, escola e inclusão social. São Paulo: Parábola.

Rosso, A. J., Tozetto, A. S., Brandt, C. F., Freire, L. I. F., Cerri, L. F., Larocca, P., \& Campos, S. X. (2011). Letramento docente: leitura e escrita do mundo e da escola. Interacções, 17, 114-134.

Souza, D., Rossi, E., \& Marassato, I. (2014). Na proa das palavras e seus sentidos: a leitura negociada entre professoras e alunos nas aulas de matemática. Linha Mestra, 24, 887-888.

Street, B. (2004). Los nuevos estudios de literacidad. In: V. Zavala, M. Niño-Murcia, \& P. Ames, Escritura y sociedad. Lima: Red para el Desarrollo de las Ciencias Sociales en el Perú.

Submetido em: 28/01/2016

Aceito em: 07/03/2016 